in minutes (each the average of three simultaneous bleedingtimes) were as follows:

\begin{tabular}{|c|c|c|c|c|c|c|}
\hline \multirow{2}{*}{$\begin{array}{c}\text { Volunteer } \\
\text { no. }\end{array}$} & \multicolumn{2}{|c|}{ Inert powder } & \multicolumn{2}{|c|}{ Sodium salicylate } & \multicolumn{2}{|c|}{ Aspirin } \\
\hline & Before & After & Before & After & Before & After \\
\hline 1 & 4.00 & $3 \cdot 75$ & $3 \cdot 15$ & $5 \cdot 15$ & 2.83 & $4 \cdot 00$ \\
\hline 2 & 3.75 & 3.00 & 2.50 & $3 \cdot 30$ & $3 \cdot 25$ & 4.90 \\
\hline 3 & $3 \cdot 25$ & $2 \cdot 75$ & $2 \cdot 00$ & 3.83 & $3 \cdot 30$ & 3.55 \\
\hline 4 & $2 \cdot 30$ & $2 \cdot 25$ & 2.00 & 1.75 & $2 \cdot 50$ & $3 \cdot 17$ \\
\hline 5 & 3.65 & 3.55 & $2 \cdot 50$ & $2 \cdot 83$ & 3.00 & $4 \cdot 40$ \\
\hline 6 & $3 \cdot 75$ & 3.50 & 2.90 & $3 \cdot 17$ & 3.50 & $2 \cdot 83$ \\
\hline 7 & 3.00 & $3 \cdot 30$ & 4.75 & 4.00 & $5 \cdot 25$ & $6 \cdot 25$ \\
\hline 8 & $3 \cdot 10$ & $2 \cdot 50$ & $2 \cdot 33$ & $2 \cdot 50$ & $2 \cdot 80$ & $4 \cdot 30$ \\
\hline 9 & $3 \cdot 30$ & 3.45 & $3 \cdot 25$ & $6 \cdot 25$ & 3.00 & $2 \cdot 65$ \\
\hline 10 & $2 \cdot 20$ & $2 \cdot 45$ & $2 \cdot 00$ & $2 \cdot 25$ & 1.90 & 3.75 \\
\hline \multicolumn{3}{|c|}{ Sum of differences -1.76} & \multicolumn{2}{|c|}{+7.76} & \multicolumn{2}{|c|}{+8.48} \\
\hline \multicolumn{3}{|c|}{ Mean of differences $-0 \cdot 176$} & \multicolumn{2}{|c|}{+0.776} & \multirow{2}{*}{\multicolumn{2}{|c|}{0.848}} \\
\hline Probability & \multicolumn{2}{|c|}{$0.1-0.2$} & \multicolumn{2}{|c|}{$0.05-0.1$} & & $<0.05$ \\
\hline
\end{tabular}

We were thus able to confirm Professor Quick's observation that aspirin slightly prolongs the bleeding-time in normal persons, but we also noted a similar but less significant trend with sodium salicylate. The difference in results may be because we used the Ivy rather than the Duke technique to determine the bleeding-time or because we administered a larger dose of sodium salicylate in an attempt to equate its pharmacological effect with that of aspirin. Our results suggest that it is too early to implicate the acetyl group as the cause of the prolonged bleeding-time.

We hope to extend our observations to a larger series of subjects and to observe the effect of these drugs on physiological functions which may control the bleeding-time in normal persons and patients with von Willebrand's disease.
Institute of Pathology,

Welsh National School of Medicine, Cardiff.

\section{A. L. BLOOM}

M. R. BEAMISH.

\section{SERUM-URIC-ACID LEVELS}

SIR,-The population of New Haven, Connecticut, seems to have a most extraordinary characteristic according to Professor Acheson and Dr. O'Brien (Oct. 8, p. 777). We have reviewed the published reports on uric-acid levels in reasonably representative samples of the Caucasian population from the U.K., the U.S., and Denmark. (Blood-donors are not considered representative samples.) Among the seven thoroughly competent reports for which the determinations were done by the spectrophotometric uricase method there are no instances in which the mean serum-uric-acid level was above $5.2 \mathrm{mg}$. per $100 \mathrm{ml}$. in males or $4.0 \mathrm{mg}$. per $100 \mathrm{ml}$. in females; yet according to Professor Acheson and Dr. O'Brien in New Haven the mean for males is $6.4 \mathrm{mg}$. per $100 \mathrm{ml}$. and for females $4.7 \mathrm{mg}$. per $100 \mathrm{ml}$.-i.e., about 6.2 and 4.5 respectively after correcting for the bias of their method. Why are the levels so high in New Haven, and why is the difference between males and females so much greater than in other Caucasian populations? Is it possible that the mean uric-acid levels should be this high without a substantial excess of gout in the community? All these rather striking points are passed without comment.

The preliminary communication of Professor Acheson and Dr. O'Brien focuses on certain "physique" variables. Specifically, they note that about $4^{\circ}{ }^{\prime}$ of uric-acid variance is accounted for by hæmoglobin level, and about $15 \%$ of the variance is accounted for by multiple regression with hæmoglobin and either body-weight or ponderal index. Then they suggest that the correlation of serum-uric-acid (s.U.A.) and achievement-oriented behaviour (A.O.B.) noted by Brooks and Mueller might be substantially altered if these physique variables are partialled out. The direction and degree of such alteration depends, of course, on the association between obesity and A.O.B., which was not reported by Brooks and Mueller. Given the correlations S.U.A. to A.O.B. $=0.66$ and S.U.A. to obesity $=0.26$, no matter what the correlation of obesity to A.O.B. the minimum partial correlation of S.U.A. to A.O.B., holding obesity constant, would be about 0.62 , but would 0.68 among university professors, in whom the correlation of obesity to A.O.B. is 0.00 .
At this point it is premature to discuss whether total bodyweight, lean body-weight, degree of obesity, or ponderal index is the most relevant variable for understanding uric-acid levels. But it is important to recognise that present evidence suggests that these variables will partial out at most only a trivial proportion of the association of S.U.A. and A.O.B.

$\begin{array}{cl}\text { University of Michigan } & \text { SIDNEY COBB } \\ \text { Institute for Social Research, } & \text { GEORGE BROOKS } \\ \text { Ann Arbor, Michigan. } & \text { STANISLAV V. KASL. }\end{array}$

*** A copy of this letter was sent by Dr. Cobb and his colleagues to Professor Acheson and Dr. O'Brien, whose reply follows.-ED. I.

Sir,-As Dr. Cobb well knows we are as intrigued as he at the high levels of serum-uric-acid in New Haven, and as our survey continues we hope will learn more of their cause. At this juncture, we can only repeat that we took the trouble to run repeated double-blind comparative analyses with another laboratory which we also believe to be "thoroughly competent". As we stated in our paper the results from the two laboratories differed a little in their mean values, but they correlated very highly.

It is at best hazardous to attempt to deduce " obesity" from weight, whether or not it is corrected for height, especially in males: we prefer the term " body bulk". Be that as it may, our regressions indicate that an "average man" of $150 \mathrm{lb}$. (10st. $10 \mathrm{lb}$.) with a hæmoglobin of $13.0 \mathrm{~g}$. per $100 \mathrm{ml}$. will have a uric acid of $5.5 \mathrm{mg}$. per $100 \mathrm{ml}$, , and one of $250 \mathrm{lb}$. (17 st. 12 lb.) with a hæmoglobin of $17.0 \mathrm{~g}$. per $100 \mathrm{ml}$. will have a uric acid of $7.3 \mathrm{mg}$. per $100 \mathrm{ml}$. These not too outrageous values can be calculated directly from our published data. It is not possible to make any direct calculation of the relation of " obesity"or of any other measure of body bulk-to serum-uric-acid, from the published work of Brooks and Mueller. ${ }^{1}$

At all events we do not question that Brooks and Mueller showed a relation between serum-uric-acid and the variable they describe as "achievement orientated behaviour". Our problem is understanding what reliable evidence led them to conclude that this relation is not only direct but causal.

Department of Epidemiology

and Public Health,

School of Medicine,

Yale University,

New Haven, Connecticut 06510.

ROY M. ACHESON

William M. O'Brien.

\section{CAN WE PREVENT IT?}

SIR,-May I be allowed to correct the impression given by the statements in your leading article (Nov. 26, p. 1171) that " death-rates from pneumonia were not demonstrably changed by the advent of chemotherapy, any more than the upward trend in diabetes mortality was halted by the discovery of insulin". In fact in both cases mortality fell substantially for the younger age-groups. In pneumonia, death-rates for 25/34year-old males fell by about nine-tenths between the early 1930 s and the late $1950 \mathrm{~s}$. By contrast pneumonia, traditionally "the old man's friend", has continued to be responsible for a growing proportion of deaths in the over-75s. A reasonable interpretation of this pattern is that lobar and other acute pneumonias in the young became treatable, while bronchopneumonia in the elderly still often fails to respond. For diabetes in 25/34-year-old males, mortality was almost halved between 1922 and 1932. Death-rates in the elderly, however, started to fall only when the introduction of chemotherap! enabled supervening infections to be controlled.

It is of course true that much of the progress towards better health must be attributed to many factors; but in the case of pneumonia those who attribute the greater part to "social betterment" may find it difficult to explain why mortality from pneumonia in young men has fallen more than five times

1. Brooks, G. W., Mueller, E. F. Am. med. Ass. 1966, 195, 121. 